\title{
PENGELOLAAN BERKELANJUTAN PERIKANAN DEMERSAL DI KAWASAN PULAU NUSA MANU DAN NUSA LEUN MALUKU TENGAH
}

\author{
Sustainable Management of Demersal Fisheries \\ in Nusa Manu Island and Nusa Leun Regions in Central Maluku
}

Oleh:

\author{
Ilham Marasabessy ${ }^{1^{*}}$, Achmad Fahrudin ${ }^{1}$, Zulhamsyah Imran ${ }^{1}$, Syamsul B.Agus ${ }^{2}$ \\ ${ }^{1}$ Program Studi Pengelolaan Sumberdaya Pesisir dan Laut FPIK-IPB, Bogor \\ ${ }^{2}$ Departemen Ilmu dan Teknologi Kelautan FPIK-IPB, Bogor \\ "Korespondensi: illo.marssy@gmail.com
}

\begin{abstract}
ABSTRAK
Usaha penangkapan ikan demersal di Seram Utara Maluku Tengah bergantung pada kemudahan bersama (open access). Para nelayan di Seram Utara mempunyai hak yang sama terhadap sumberdaya ikan karena tangkapan berpindah dari satu tempat ke tempat lain, dengan resiko yang harus dihadapi. Kegiatan penangkapan ikan demersal memerlukan alat tangkap yang disesuaikan dengan lokasi tangkap dan jenis ikan yang ingin diperoleh. Pulau Nusa Manu dan Pulau Nusa Leun masuk dalam kategori pulau kecil dengan luas sekitar $0,31 \mathrm{~km}^{2}$ dan $0,73 \mathrm{~km}^{2}$. Kawasan ini memiliki potensi sumberdaya ikan demersal yang besar dan sejak lama dimanfaatkan oleh masyarakat di sekitar kawasan kedua pulau. Penelitian dilakukan dari bulan September sampai Desember 2016. Dengan menggunakan metode evaluatif deskriptif untuk mendapatkan data primer, data bentang alam pulau diperoleh dari citra Arcgis Imagery 2016, sedangkan penentuan koordinat fishing ground dengan melakukan tracking penangkapan ikan. Kemudian data diproses menggunakan analisis spasial dengan aplikasi Sistem Informasi Geografis (ArcGIS) untuk menentukan fishing ground potensial. Laju eksploitasi ikan demersal pada kawasan kedua pulau mulai berada dalam kondisi tekanan penangkapan dengan nilai 52-54\% sehingga perlu dilakukan perbaikan untuk meminimalisir dampak penurunan sumberdaya ikan demersal yang lebih besar.
\end{abstract}

Kata kunci: Daya dukung, perikanan demersal, pulau kecil dan pengelolaan berkelanjutan.

\begin{abstract}
Demersal fishing effort at North Seram in Central Maluku depends on the ease of the joint (open access). The fishermen here have the same rights to fisheries resources as the catch moves from place to place, with risks to be faced. Demersal fishing activities require fishing gear adapted to catch locations and types of fish to be obtained. Nusa Manu Island and Nusa Leun fall into the category of small islands with an area of about $0.31 \mathrm{~km}^{2}$ and $0.73 \mathrm{~km}^{2}$. This area has a large demersal fish resource potential and has long been utilized by the community around the area of both islands. The study was conducted from September to December 2016. Using descriptive evaluative method to obtain primary data, while the island's landscape was obtained from Arcgis Imagery 2016 image, whereas the determination of coordinate fishing ground by tracking the fishing. Then the data is processed using spatial analysis with Geographic Information System (ArcGIS) application to determine potential fishing ground. The demersal exploitation rate of the two islands begins under conditions of arrest pressure with a value of 52-54\% so that improvement needs to be done to minimize the impact of larger demersal fish resource depletion.
\end{abstract}

Keywords: Carrying capacity, demersal fishery, small island, and sustainable management. 


\section{PENDAHULUAN}

Pulau-pulau kecil di daerah tropis sangat erat kaitannya dengan terumbu karang, sehingga kawasan ini memiliki banyak spesies ekonomis yang menjadikan ekosistem terumbu karang sebagai habitatnya seperti ikan kerapu, kakap, napoleon, teripang dan lain-lain (Micheli et al. 2013). Secara umum Pulau Nusa Manu dan Nusa Leun memiliki karateristik khas terkait sumberdaya hayati seperti ikan karang yang berasosiasi dengan terumbu karang di sekitar kawasan pulau tersebut (Ayal 2009).

Pulau Nusa Manu dan Pulau Nusa Leun masuk dalam kategori pulau kecil dengan luas sekitar 0,31 km² dan 0,73 km². Hal ini tertuang dalam UU No 27 Tahun 2007, jo UU No 1 Tahun 2014 Pasal 1 Ayat 3 tentang Pengelolaan Wilayah Pesisir dan Pulau-Pulau Kecil, yaitu pulau kecil adalah pulau dengan luas daratan kurang atau sama dengan $2.000 \mathrm{Km}^{2}$. Pemanfaatan potensi sumberdaya perikanan di daerah ini belum optimal dilihat dari besarnya potensi yang tersedia, tahun 2014 telah dimanfaatkan sebesar 168.953,13 ton (17,41\%). Dalam eksploitasi potensi dimaksud, perlu ditunjang dengan berbagai faktor penunjang produksi seperti Rumah Tangga Perikanan (RTP), Armada Penangkapan, Unit Penangkapan dan lain-lain. (Dinas Kelautan dan Perikanan Kabupaten Maluku Tengah 2014). Rendahnya tingkat pemanfaatan ini adalah akibat dari keterbatasan armada tangkap yang tersedia berupa perahu tanpa motor dan perahu motor tempel milik nelayan tradisional dengan produktivitas tangkapan yang masih rendah (Sudirman dan Mallawa 2012). Meskipun demikian kegiatan usaha penangkapan ikan yang terbuka (open access) jika dilakukan tanpa pengaturan dan pengawasan dapat mengancam ekosistem dan sumberdaya alam di sekitar kawasan tersebut. Potensi perikanan ikan demersal telah lama dimanfaatkan oleh nelayan di Maluku dan sekitarnya sebagai daerah fishing ground untuk memenuhi kehidupan ekonomi masyarakat (Noija et al. 2014). Begitu juga perairan Pulau Nusa Manu dan Nusa Leun yang berada di wilayah Seram Utara merupakan lokasi penangkapan ikan demersal, karena letaknya yang relatif lebih dekat dengan desa pesisir (maindland) sehingga mudah dijangkau oleh nelayan.

Berdasarkan potensi yang ada di kedua pulau ini, maka tersirat pertanyaan ilmiah yang mendasar, apakah kawasan kedua pulau dapat dikembangkan sebagai kawasan fishing ground potensial. Untuk itu penelitian ini dilakukan dengan tujuan mengidentifikasi fishing ground potensial ikan demersal di Pulau Nusa Manu dan Nusa Leun.

\section{METODE PENELITIAN}

Penelitian ini berlokasi pada Pulau Nusa Manu dan Nusa Leun, secara geografis berbatasan dengan: bagian utara dengan Laut Seram Utara, bagian selatan dengan Negeri Sawai, bagian barat dengan Negeri Saleman dan bagian timur dengan Desa Opin.

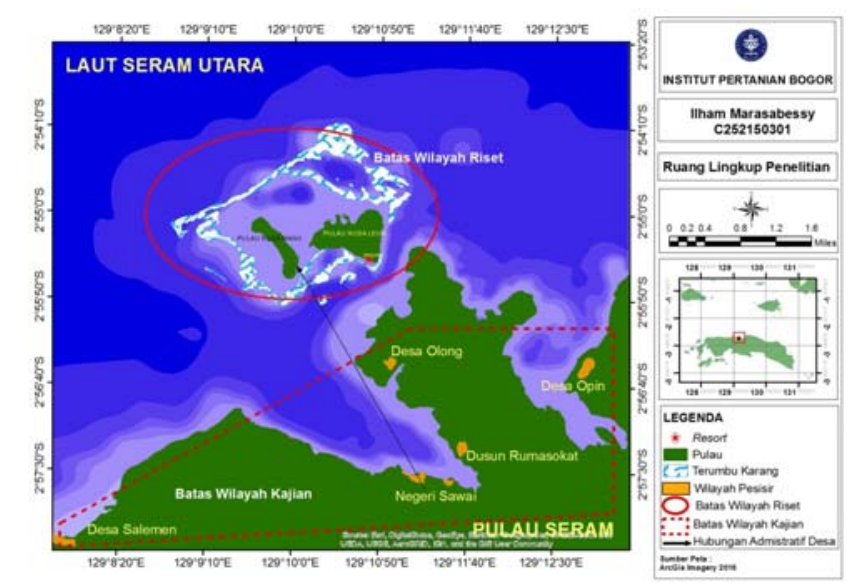

Gambar 1 Ruang lingkup penelitian 
Jenis data yang digunakan dalam penelitian ini meliputi data primer dan data sekunder. Data primer diperoleh dengan melakukan pengukuran langsung secara in situ meliputi data oseanografi seperti; suhu, salinitas, $\mathrm{pH}$, oksigen terlarut, pasang surut, batimetri, gelombang dan arus. Data sekunder meliputi data RTRW, potensi dan pemanfaatan sumberdaya alam (SDA) secara existing, didapatkan dari beberapa instansi terkait seperti, kantor Badan Perencanaan Pembangunan Daerah (BAPPEDA), Badan Pusat Statistik (BPS), Dinas Kelautan dan Perikanan Kabupaten Maluku Tengah dan Provinsi Maluku serta kantor terkait lainnya di Kabupaten Maluku Tengah dan Kota Ambon. Untuk data peta yang dipakai adalah peta citra satelit yang diperoleh dari citra Acrgis Imagery 2016, serta peta dasar yang diperoleh dari Badan Informasi dan Geospasial (BIG). Alat yang digunakan antara lain: $\mathrm{pH}$ meter, DO meter, layangan arus, palem pasut, refraktometer, digital thermometer dan GPS.

Pemetaan daerah potensial penangkapan ikan dilakukan dengan cara overlay titik tangkapan ikan yang diperoleh melalui tracking menggunakan GPS dengan mengikuti jalur penangkapan ikan yang umumnya dilakukan oleh nelayan setempat selama 3 bulan (September - Desember) dengan interval pengulangan setiap 2 minggu, sehingga diperoleh waktu pengamatan untuk tracking penangkapan ikan ialah sebanyak 6 pengulangan. Jenis ikan hasil tangkapan, panjang dan bobot ikan yang diperoleh dari lokasi pengambilan data dibagi dalam 3 kategori yaitu hasil tangkapan tinggi, hasil tangkapan sedang dan hasil tangkapan rendah jika bobot tangkapan kurang.

Kesesuaian fishing ground dilakukan dengan menggunakan metode analisis spasial dan menyesuaikan titik koordinat saat melakukan tracking alur/lokasi penangkapan ikan dengan nelayan, selanjutnya titik koordinat tersebut dicatat dan diolah dengan menggunakan Sistem Informasi Geografis (SIG) untuk membuat kesesuaian daerah penangkapan ikan yang potensial. Area perairan di sekitar Pulau Nusa Manu dan Nusa Leun yang paling sering dijadikan target location fishing ground ditetapkan sebagai area yang berpotensi untuk dijadikan fishing ground potensial di kawasan tersebut. Untuk mengetahui laju eksplotasi sumberdaya ikan demersal, maka dilakukan analisis berdasarkan rekruitmen dan mortalitas penangkapan ikan dalam kawasan kedua pulau tersebut seperti:

\section{Identifikasi Kelompok Ukuran Ikan}

Sebaran frekuensi panjang digunakan untuk menentukan kelompok ukuran yang dapat menduga kelompok umur ikan. Data panjang total ikan dikelompokkan ke dalam beberapa kelas panjang sedemikian, sehingga kelas panjang ke-i memiliki frekuensi (fi). Pendugaan kelompok umur dilakukan dengan analisis frekuensi panjang ikan menggunakan metode NORMSEP (Normal Separation) (FISAT II, FAO-ICLARM Stock Assesment Tool) untuk menentukan sebaran normalnya.

\section{Pendugaan Parameter Pertumbuhan Sumberdaya Ikan}

Koefisien pertumbuhan yang digunakan mengikuti model von Bertalanffy (Sparre dan Venema 1999) yang dirumuskan sebagai:

$$
L t=L \infty[1-\exp (-(t-t 0))]
$$

$L t$ adalah ukuran ikan pada umur $t(\mathrm{~cm}), L^{\infty}$ adalah panjang asimptotik $(\mathrm{cm}), K$ adalah koefisien pertumbuhan (tahun-1), dan t0 adalah umur hipotesis ikan pada panjang nol (tahun). Koefisien pertumbuhan $K$ dan $L \infty$ pada (2) diduga dengan menggunakan metode Ford Walford yang diturunkan berdasarkan pertumbuhan von Bertalanffy untuk $L t$ pada saat $t+\Delta t$ dan $t$ sedemikian sehingga:

$$
L t+\Delta t=L \infty(1-\exp (-K \Delta t)+\exp -K \Delta t L t)
$$

Persamaan di atas diduga melalui persamaan regresi linear $\mathrm{y}=\mathrm{b} 0+\mathrm{b} 1 \mathrm{x}$, dengan $L t$ sebagai absis (x), $L t+\Delta t$ sebagai ordinat (y), b0= $L \infty(1-\mathrm{b})$, dan $\mathrm{b} 1=\exp (-K \Delta t)$. Nilai $K$ dan $L \infty$ diduga dengan rumus: 


$$
\begin{aligned}
& K=-(1 \Delta t) \ln b \\
& L^{\infty}=b 01-b 1
\end{aligned}
$$

Laju Mortalitas dan Laju Eksploitasi Sumberdaya Ikan

Menurut Sparre dan Venema 1999 parameter mortalitas meliputi mortalitas alami (M), mortalitas penangkapan (F), dan mortalitas total (Z). Laju mortalitas total (Z) diduga dengan kurva tangkapan yang dilinearkan berdasarkan data panjang sedemikian sehingga diperoleh hubungan:

$\ln C(L I+L 2) \Delta t(L 1, L 2)=\mathrm{h}-\mathrm{Z} \mathrm{t}(L 1+L 2) 2)$.

Persamaan (5) diduga melalui persamaan regresi linear sederhana $y=b 0+b 1 x$, dengan $y=\ln C$ $(L I+L 2) \Delta \mathrm{t}(L 1, L 2)$ sebagai ordinat, $\mathrm{x}=(L 1+L 2) 2)$ sebagai absis, dan $\mathrm{Z}=-\mathrm{b} 1$ (Lampiran 1$)$.

Laju mortalitas alami (M) diduga dengan menggunakan rumus empiris Pauly (1980) in Sparre dan Venema (1999) sebagai berikut:

$\mathrm{M}=\exp (-0.0152-0.279 \ln L \infty+0.6543 \ln K+0.463 \ln T)$

$\mathrm{M}$ adalah mortalitas alami (per tahun), dan Tadalah suhu rata-rata perairan (0C).

Setelah laju mortalitas total (Z) dan laju mortalitas alami (M) diketahui maka laju mortalitas penangkapan dapat ditentukan melalui hubungan:

$\mathrm{F}=\mathrm{Z}-\mathrm{M}$

Selanjutnya Pauly (1984) menyatakan laju eksploitasi dapat ditentukan dengan membandingkan $\mathrm{F}$ dengan $\mathrm{Z}$ sebagai berikut:

$E=F / Z$

F adalah laju mortalitas penangkapan (per tahun), $\mathrm{Z}$ adalah laju mortalitas total (per tahun), dan $\mathrm{E}$ adalah tingkat eksploitasi.

\section{HASIL DAN PEMBAHASAN}

\section{Identifikasi Kelompok Ukuran Ikan}

Teluk Sawai memiliki bentuk topografi yang unik dan keanekaragaman hayati yang tinggi seperti pada wilayah teluk secara umum (Coll et al. 2010). Ekosistem yang beragam berpengaruh terhadap aktifitas yang berlangsung di sekitar kawasan tersebut dalam upaya mengambil sumberdaya bagi manusia termasuk kegiatan penangkapan ikan (Coll et al. 2010; Micheli et al. 2013). Berdasarkan proses tracking fishing ground dengan nelayan yang melakukan kegiatan penangkapan ikan, maka dapat diketahui bahwa lokasi penangkapan ikan berada di sekitar Pulau Nusa Manu dan Nusa Leun hingga ke arah utara Laut Seram sekitar $3 \mathrm{~km}$ atau setara dengan 1,61987 mil laut $(1 \mathrm{Km}=0,53995$ mil laut).

Pada Gambar 2, diketahui bahwa fishing ground nelayan lebih dominan berada di sekitar Pulau Nusa Manu dan Nusa Leun, hanya beberapa nelayan yang bergerak ke arah luar (bagian utara) dan sebagian ke arah dalam (bagian barat) Teluk Sawai. Kecenderungan ini dikarenakan armada penangkapan nelayan yang relatif kecil dan tergolong sederhana sehingga tidak optimal digunakan saat melakukan kegiatan penangkapan ikan dengan fishing ground yang jauh. Selain itu, faktor lain yang menyebabkan terpusatnya kegiatan penangkapan ikan pada Pulau Nusa Manu dan Nusa Leun ialah karena keberadaan terumbu karang (fringing reef) yang luas dengan bentuk melingkari kedua pulau tersebut, sehingga merupakan habitat yang disukai oleh berbagai jenis ikan karang seperti ikan kerapu, kakap, bubara dan lain-lain. Hal ini sesuai dengan pendapat (Budiman 2006; Najamuddin 2012) bahwa produktivitas primer suatu perairan berkaitan erat dengan baik buruknya ekosistem di 
sekitarnya, di mana sebagian besar ikan karang menjadikan terumbu karang sebagai tempat mencari makanan (feeding ground), daerah perkembang-biakan (spawning ground), tempat berlindung (protection ground) dan daerah asuhan (nursery ground).

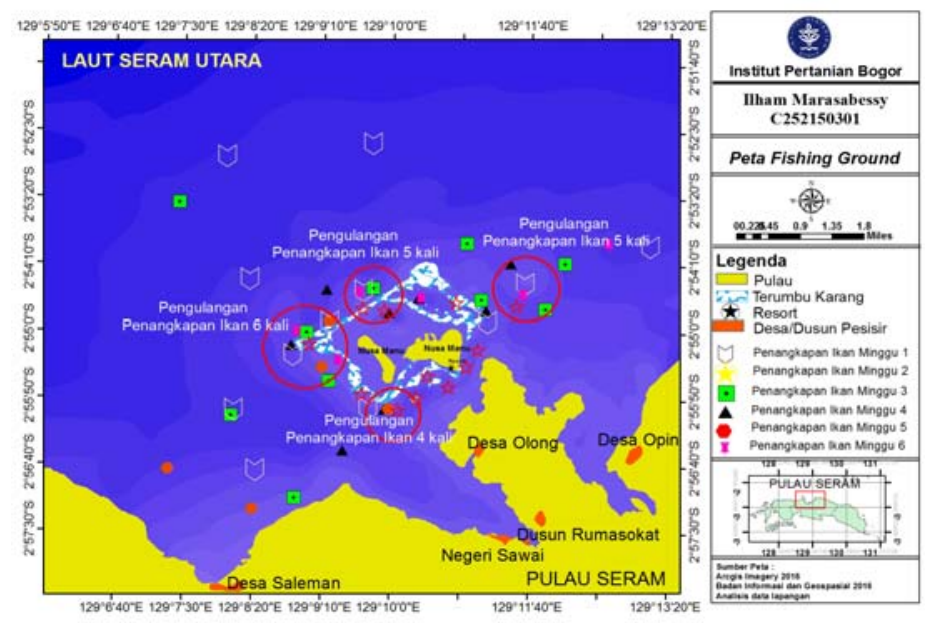

Gambar 2 Fishing ground nelayan Negeri Sawai dan sekitarnya

Berdasarkan hasil pengamatan kegiatan penangkapan ikan terlihat bahwa, lokasi fishing ground yang paling sering didatangi ialah pada bagian barat dan utara Pulau Nusa Manu juga sebagian ada di bagian timur Pulau Nusa Leun. Hal ini diketahui dengan banyaknya armada penangkapan ikan yang berada di sekitar kawasan tersebut. Selama 6 kali proses tracking fishing ground, secara keseluruhan nelayan melakukan kegiatan penangkapan ikan di tempat ini secara berulang. Hal ini disebabkan karena faktor kebiasaan nelayan dalam melakukan penangkapan ikan dan hasil tangkapan ikan target yang banyak diperoleh. Kecenderungan hal ini terjadi, karena secara ekologi lokasi tersebut memiliki ekosistem terumbu karang yang baik (Nybaken 1998; Tuwo 2012). Kondisi berbeda terlihat pada lokasi bagian selatan Pulau Nusa Leun (sekitar resort), di mana hasil tangkapan ikan tidak banyak diperoleh pada lokasi tersebut.

Pendeteksian daerah penangkapan ikan untuk suatu kegiatan usaha penangkapan ikan bagi nelayan tradisonal memiliki urgensi yang cukup tinggi di perairan Pulau Nusa Manu dan Nusa Leun. Dalam kegiatan penangkapan ikan keberhasilan mendapatkan hasil tangkapan yang optimal dengan akurat dan cepat sangat diperlukan, selain dapat menghemat waktu, juga dapat menekan biaya operasional penangkapan ikan (cost fishing effort), sehingga perlu mempertimbangkan beberapa hal berikut; 1. Tingkah laku ikan, berhubungan dengan penyebaran dan keberadaan (availability) ikan yang menjadi tujuan penangkapan; 2. Persaingan nelayan di sekitar kawasan kedua pulau yang cukup tinggi untuk memperebutkan daerah penangkapan ikan; dan 3. Kemampuan usaha nelayan yang terbatas. Hal ini sesuai dengan pendapat (Simbolon 2011) penentuan daerah fishing ground sangat tergantung pada tingkah laku ikan dan kondisi daerah penangkapan yang selalu berubah (dinamis) sesuai dengan perubahan parameter oseanografi. Kemampuan nelayan tradisional yang terbatas menyebabkan persaingan dalam mencari fishing ground yang potensial.

\section{Armada Penangkapan Ikan Demersal}

Jenis armada penangkapan ikan yang umumnya dipergunakan oleh nelayan Sawai dan sekitarnya ialah perahu tanpa motor dan perahu motor tempel (mesin tempel 15/25 PK dan mesin ketinting) dengan ukuran yang bervariasi dari jukung, perahu kecil, sedang sampai yang besar. Kebiasaan nelayan penangkap ikan di wilayah ini ialah dengan menggunakan alat tangkap pancing dengan target ikan tangkapan yaitu jenis ikan demersal. Armada pancing yang beroperasi di sekitar 
perairan Teluk Sawai memiliki kapasitas yang kecil yaitu $<5$ GT. Beberapa desa pesisir yang sering memanfaatkan lokasi fishing ground di sekitar kawasan kedua pulau antara lain; Negeri Sawai, Negeri Saleman, Dusun Rumasokat, Desa Olong dan Desa Opin. Kapasitas armada penangkapan ikan pada beberapa desa pesisir tersebut masih relatif kecil, sehingga operasi penangkapan yang dilakukan one day trip atau sehari melaut, dengan beberapa selang waktu/periode (Sudirman dan Mallawa 2012).

Penangkapan ikan dapat dilakukan dalam sekali keberangkatan dan dapat juga dilakukan dalam beberapa kali dalam sehari. Jika dilakukan dalam sekali keberangkatan biasanya nelayan menyiapkan perbekalan untuk makan, tetapi jika tidak maka nelayan akan pulang ke rumah untuk makan dan beristirahat, kemudian akan kembali lagi melakukan kegiatan penangkapan ikan di periode waktu lainnya pada hari yang sama. Jenis armada penangkapan ikan yang digunakan oleh nelayan Sawai dan sekitarnya dapat dilihat pada (Gambar 3).
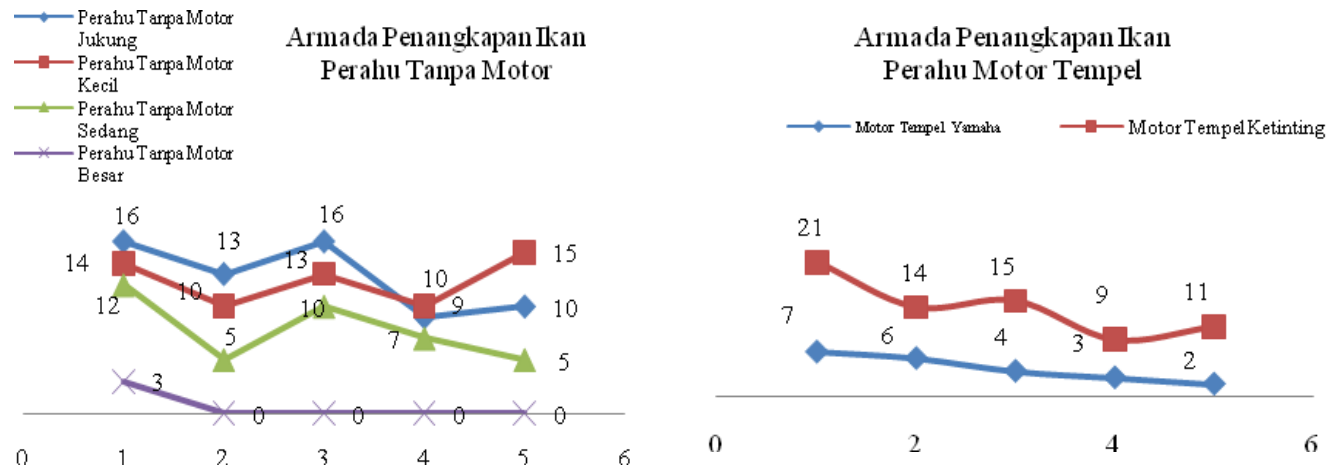

Gambar 3 Jenis armada penangkapan ikan yang digunakan nelayan

Kegiatan penangkapan ikan demersal oleh nelayan sekitar kawasan kedua pulau, umumnya dilakukan secara sendiri tanpa membawa anggota nelayan, hal ini disebabkan karena armada tangkap yang relatif berukuran kecil dan masih tergolong tradisional. Variasi operasi penangkapan ikan tidak menentu antara nelayan satu dengan yang lain. Selama satu bulan nelayan melakukan operasi penangkapan ikan selama 20 hari dan 10 hari digunakan untuk istirahat dan memperbaiki kerusakan alat tangkap juga perahu, walaupun tidak mutlak penentuan periode waktu penangkapan ikan itu dilakukan, karena dapat disesuaikan dengan kondisi pasar, dan musim penangkapan ikan.

\section{Alat Penangkapan Ikan Demersal}

Alat penangkapan ikan berupa pancing yang umumnya digunakan oleh nelayan Sawai dan sekitarnya adalah merupakan alat tangkap pancing tradisional yang telah dipakai secara turun temurun dan merupakan kebiasaan yang digunakan saat kegiatan penangkapan ikan (Gambar 4). Ukuran mata pancing/kail yang digunakan ialah dengan nomor 5/0, 6/0, 7/0 dan 8/0 sedangkan ukuran benang/tasi/tali bervariasi disesuaikan dengan ukuran mata pancing (Dinas Kelautan dan Perikanan Kabupaten Maluku Tengah 2016). 


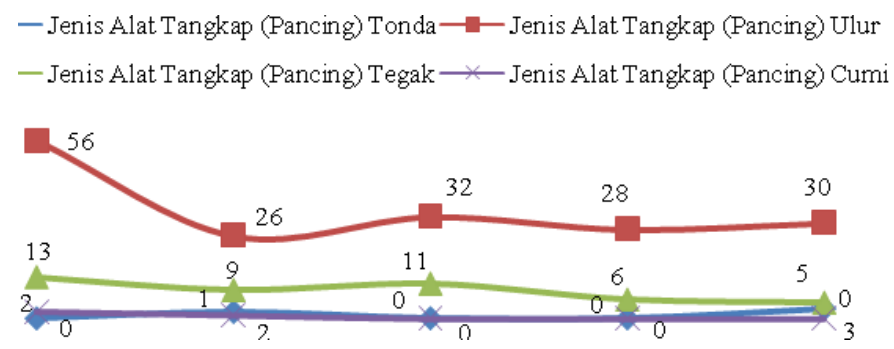

Gambar 4 Jenis alat tangkap ikan yang digunakan nelayan

Kegiatan penangkapan ikan demersal oleh nelayan sekitar kawasan kedua pulau, umumnya jenis pancing yang digunakan oleh nelayan Sawai dan sekitarnya lebih diperuntukkan untuk proses penangkapan ikan demersal, seperti pancing ulur dan pancing tegak. Berdasarkan data yang diperoleh jumlah nelayan yang menggunakan pancing ulur dan tegak pada 5 wilayah di sekitar Teluk Sawai lebih banyak, sedangkan untuk jenis pancing tonda dan cumi jumlahnya sangat sedikit. Negeri Sawai memiliki nelayan dengan penggunaan alat tangkap pancing ulur sebanyak 56 nelayan dan pancing tegak sebanyak 13 nelayan, jumlah ini lebih tinggi jika dibandingkan dengan nelayan lainnya. Sedangkan penggunaan jenis kedua pancing ini lebih rendah digunakan oleh nelayan di Desa Opin dan Olong.

Perbedaan penggunaan jenis alat pancing yang digunakan nelayan di sekitar kawasan ini berbanding lurus dengan jumlah nelayan dan armada penangkapan ikan di wilayah masing-masing. Faktor kebiasaan dan pengalaman dalam pengoperasian alat tangkap ikan menjadi faktor yang membedakan banyaknya jumlah nelayan pada desa pesisir di wilayah tersebut. Selain itu, diketahui bahwa sebagian nelayan di desa pesisir telah beralih profesi dari nelayan utama menjadi guiters bagi wisatawan yang berkunjung. Kegiatan penangkapan ikan hanya dilakukan di waktu-waktu senggang. Untuk jenis pancing tonda dan cumi secara umum tidak terlalu banyak digunakan oleh nelayan setempat karena kesesuaian konstruksi armada penangkapan ikan yang relatif lebih kecil jika digunakan untuk pancing tonda, teknik pengunaan alat tangkap dan jenis ikan target tangkapan yang dipancing cenderung berbeda. Hal ini sesuai dengan penjelasan (Sudirman dan Mallawa 2012) bahwa pengoperasian alat tangkap pancing tonda akan lebih efektif jika menggunakan kapal/long boat dengan tenaga mesin motor yang relatif besar, dikarenakan jenis ikan target tangkapan ialah pelagis besar (tuna, tenggiri, barakuda dan cakalang) yang cenderung bergerak cepat.

\section{Hasil Tangkapan Ikan Demersal}

Total jumlah hasil tangkapan ikan demersal yang diperoleh ialah 349 ekor dengan pembagian persentase masing-masing ikan dari 5 famili antara lain; famili Seranidae, Caranidae, Scaridae, Siganidae dan Lutjanidae. Dari beberapa famili tersebut diperoleh 8 jenis ikan dengan persentase yaitu ikan kerapu merah/sunuk (Plectropomus maculatus) sebanyak 4\%, (Plectropomus leopardus) sebanyak 37\%, kerapu macan (Epinephelus fuscoguttatus) sebanyak 11\%, ikan kakatua (Scarus sp) sebanyak 5\%, ikan kuwe/bubara/Giant Trevally (Caranx sexfaciatus) sebanyak 23\%, baronang/samandar (Siganus sp) sebanyak 11\% dan ikan kakap (Lutjanus spp) sebanyak 8\% sedangkan untuk jenis ikan kerapu tikus (Chromileptes altivelis) hanya diperoleh sebanyak 4 ekor atau sebesar $1 \%$ dari jumlah total ikan hasil tangkapan yang diperoleh.

Tingginya hasil tangkapan dari kelompok jenis ikan demersal ini dikarenakan fishing ground di sekitar kedua pulau ini merupakan habitat bagi ikan karang juga karena target tujuan ikan tangkapan ialah dari jenis ikan tersebut. Banyaknya hasil tangkapan yang diperoleh sering terjadi karena spesies yang tertangkap umumnya berasal dari ukuran mata pancing yang sama, terutama di perikanan ikan campuran, di mana akan sulit untuk mengurangi tangkapan spesies tunggal ketika 
beberapa spesies dapat tertangkap bersama (Ulrich et al. 2011; Mortensen et al. 2018). Hal ini terlihat dari ukuran mata pancing, umpan dan teknik pemancingan yang lebih difokuskan untuk penangkapan jenis ikan karang. Hasil tangkapan nelayan di sekitar perairan Pulau Nusa Manu dan Nusa Leun dapat dilihat pada (Gambar 5).

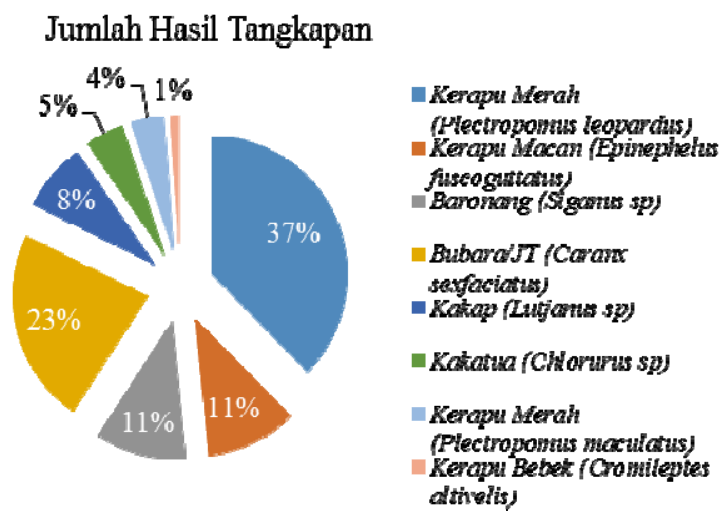

Gambar 5 Persentase jumlah hasil tangkapan ikan

\section{Daya Dukung Penangkapan Ikan Demersal}

Laut Ambon dan Seram Maluku merupakan salah satu daerah penangkapan (fishing ground) potensial dari berbagai jenis sumberdaya perikanan. Mulai dari perairan pantai (in shore) di permukaan perairan (pelagic), hingga lepas pantai (off shore), laut dalam (deep sea). Sumberdaya perikanan di wilayah ini sejak lama dimanfaatkan secara turun temurun oleh nelayan setempat (Noija et al. 2014). Lebih lanjut (Halpern et al. 2008) menjelaskan bahwa peningkatan tekanan dan dampak kumulatif pada ekosistem laut dapat terus terjadi, sehingga perlu dilakukan pendekatan terencana untuk pengelolaan ruang laut. Menurut (Purbayanto et al. 2010) penggunaan setiap jenis teknologi penangkapan ikan mulai dari yang sederhana hingga yang moderen sedikit atau banyak akan memberikan dampak negatif terhadap sumberdaya ikan dan lingkungan. Pengaruh dari dampak tersebut berbeda sesuai besar pemanfaatan SDA dalam suatu kawasan seperti; daya penangkapan ikan (fishing power) dan intensitas penangkapan ikan (duration and frequency fishing effort).

Identifikasi dan pemetaan ekosistem serta komponen sosial-ekonomi adalah bagian penting dari proses perencanaan tata ruang pesisir dan lautan secara menyeluruh dengan pendekatan manajemen tata ruang berbasis ekosistem (Katsanevakis et al. 2011). Dalam konteks itu, pemetaan kegiatan penangkapan ikan dan identifikasi daerah tangkapan ikan menjadi sangat penting. Penentuan daerah yang penting dalam proses kegiatan penangkapan ikan dilakukan untuk memperkirakan kesesuian fishing ground dan membatasi kegiatan penangkapan ikan di daerah tertentu. Memperkirakan fishing ground potensial tersebut merupakan komponen penting dari perencanaan keberlanjutan sumberdaya perikanan yang sistematis, dengan tujuan untuk mencapai kelestarian sumberdaya alami. Salah satu pendekatan daya dukung penangkapan ikan ialah mengetahui pendugaan laju ekploitasi penangkapan ikan pada suatu kawasan tertentu (Ban dan Klein 2009 ; Mazor et al. 2014). Untuk mengetahui laju eksplotasi suatu sumberdaya ikan perlu dilakukan analisis pada sumberdaya dimaksud berdasarkan rekruitmen dan mortalitas penangkapan ikan dalam suatu kawasan.

\section{Rekruitmen Ikan Demersal yang Dominan Tertangkap}

Rekruitmen merupakan masuknya individu baru yang sudah dapat dieksploitasi ke dalam area penangkapan. Individu baru tersebut merupakan hasil reproduksi yang telah tersedia pada tahapan tertentu dari suatu siklus daur hidup (Effendie 1979; Wudji et al. 2012; Kartini et al. 2017). Sedangkan laju pertumbuhan merupakan peningkatan dalam satuan panjang atau bobot per unit waktu, ikan 
tidak berhenti tumbuh setelah mencapai kematangan seksual (Rifai dan Samal 2013). Berdasarkan pengamatan terhadap hasil tangkapan nelayan kawasan Pulau Nusa Manu dan Nusa Leun yang di daratkan pada pasar tradisional Negeri Sawai pada bulan September hingga Desember 2016, diperoleh beberapa jenis ikan demersal yang dominan dan secara time series sebanyak 6 kali pengamatan selama 3 bulan yaitu ikan kerapu merah (Plectropomus leopardus) dan bubara (Caranx sexfaciatus) dengan jumlah yang relatif banyak dibandingkan jenis ikan demersal lainnya. Dalam perhitungan parameter rekruitmen ikan mula-mula diduga melalui analisis pemisahan kelompok ukuran. Analisis pemisahan kelompok ukuran panjang ikan dilakukan dengan metode NORMSEP dengan bantuan program FISAT II. Pemisahan kelompok ukuran ikan didasarkan pada sebaran kelas frekuensi panjang. Berdasarkan data kelompok ukuran ikan maka dapat dilakukan pendugaan parameter pertumbuhan meliputi nilai koefisien pertumbuhan (k), panjang asimptotik tubuh ikan ( $\mathrm{L} \infty)$, dan umur teoritik ikan pada saat panjang ikan nol (t0) yang dianalisis dengan menggunakan model von Bertalanffy.

\section{Jenis Ikan Kuwe/Bubara (Caranx sexfaciatus)}

Berdasarkan hasil perhitungan rekruitmen ikan kuwe/bubara (Caranx sexfaciatus) memiliki nilai $\mathrm{k}$ yang lebih kecil dibandingkan ikan kerapu merah (Plectropomus leopardus). Hal ini menunjukkan bahwa ikan bubara tumbuh lebih lambat mencapai $\mathrm{L} \infty$, sehingga ukuran ikannya lebih besar dibandingkan ikan lainnya, ukuran bobot jenis ikan ini dapat mencapai 6-10 Kg. Hal ini sesuai dengan pendapat (Effendie 1979; Agustina 2015) jika suatu jenis ikan mengalami pertumbuhan lebih lambat saat mencapai $\mathrm{L} \infty$, maka ukuran tubuh ikan akan lebih besar.

Berdasarkan Gambar 6, parameter pertumbuhan ikan kuwe/bubara (Caranx sexfaciatus), pada fishing ground Pulau Nusa Manu dan Nusa Leun diperoleh nilai $\mathrm{L}_{\infty}=241,5$ dan nilai $\mathrm{k}=0,47$, pertumbuhan yang lambat pada jenis ikan ini terjadi pada awal tahun yaitu pada bulan 1 sampai 5 yakni sebesar 4,91\% dan 7,09\%, kemudian mengalami peningkatan di bulan 6 sebesar 10,88\% hingga puncaknya pada bulan 8 yaitu sebesar 16,32\%. setelah itu mulai mengalami penurunan secara bertahap pada bulan 9 dari 14,00\% menjadi 7,31\% di bulan 11 dalam kurun waktu satu tahun. Kecenderungan pola rekruitmen ikan kuwe/bubara dengan ukuran tubuh yang relatif besar terlihat di alam pada saat melakukan pengamatan di lokasi, di mana ukuran tubuh ikan jenis ini diperoleh lebih besar dari jenis ikan kerapu, kakatua, kakap, baronang dan kerapu bebek.
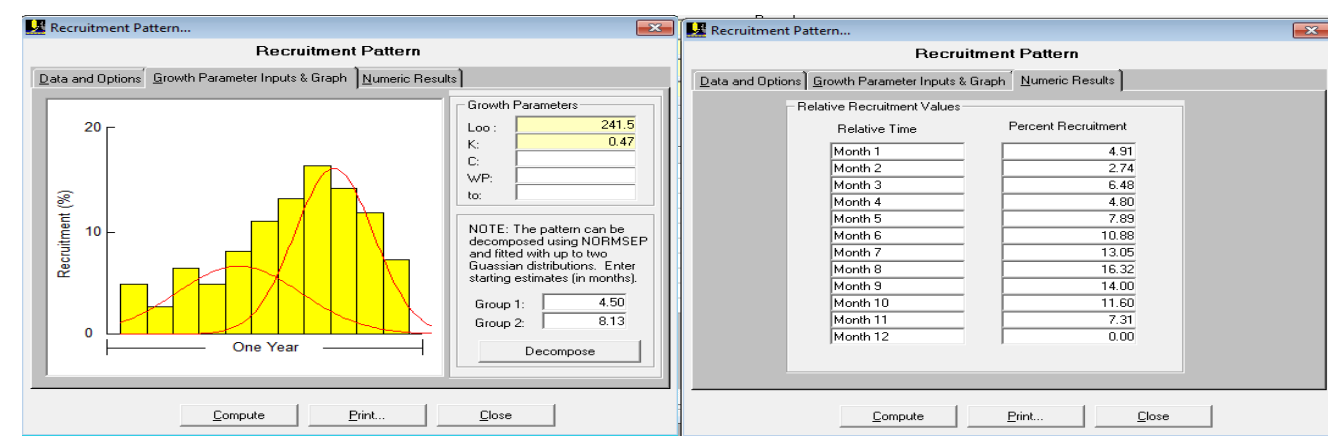

Gambar 6 Parameter dan nilai pertumbuhan ikan kuwe/bubara (Caranx sexfaciatus) selama satu tahun di sekitar perairan Pulau Nusa Manu dan Nusa Leun

\section{Jenis Ikan Kerapu (Plectropomus leopardus)}

Menurut Shapiro (1987) kerapu merupakan salah satu jenis ikan yang hidup di daerah terumbu karang dan bersifat protogynous hermaprodit (perubahan kelamin dari betina menjadi jantan). Pemijahan ikan kerapu Plectropomus sp dapat secara alami (natural spawning), pemijahan (stripping/artifical fertilization) dan pijah rangsang (induced spawning). Untuk parameter pertumbuhan ikan kerapu merah (Plectropomus leopardus), pada fishing ground Pulau Nusa Manu dan Nusa Leun diperoleh nilai $\mathrm{L} \infty=239,4$ dan nilai $\mathrm{k}=0,61$. Pertumbuhan ikan kerapu merah (Plectropomus leopardus) memiliki nilai $\mathrm{k}$ yang relatif lebih besar, hal ini menunjukan jenis-jenis 
ikan tersebut dapat tumbuh lebih cepat mencapai L $\infty$, sehingga ikan-ikan jenis ini memiliki ukuran yang relatif lebih kecil, yaitu sekitar 1-5 Kg. Perbedaan nilai L $\infty$ berhubungan erat dan dipengaruhi oleh nilai k spesies ikan demersal yang diperoleh.

Berdasarkan Gambar 7, diketahui pertumbuhan ikan kerapu merah agak lambat terjadi pada awal tahun di bulan 1 yaitu sebesar 1,96\% sampai bulan 2 yakni 4,00\%. Kemudian mulai mengalami peningkatan saat masuk bulan 3 sebesar 9,80\% dan meningkat terus pada bulan 4 sebesar 12,10\% hingga mengalami puncaknya pada bulan 5 sebesar 15,66\%. Setelah itu rekrutmen ikan ini cenderung bertahan sejak bulan 6 dari 13,63\% hingga sampai pada bulan 9 dan 10 sebesar 10,42\% dan 8,48\%. Kemudian mengalami penurunan hingga terendah sebesar $1,14 \%$ pada bulan 11 . Kondisi ini terlihat di lokasi saat melakukan pengamatan terhadap hasil tangkapan nelayan di kedua pulau tersebut, di mana pada bulan 9 sampai 10 jumlah hasil tangkapan ikan kerapu masih banyak diperoleh. Hal ini sesuai dengan pendapat (Mayunar 1992; Shapiro 1987) bahwa dalam setahun ada kecenderungan terjadi 2-3 musim puncak pemijahan ikan kerapu merah (Plectropomus leopardus) dari bulan Maret, September hingga Oktober.
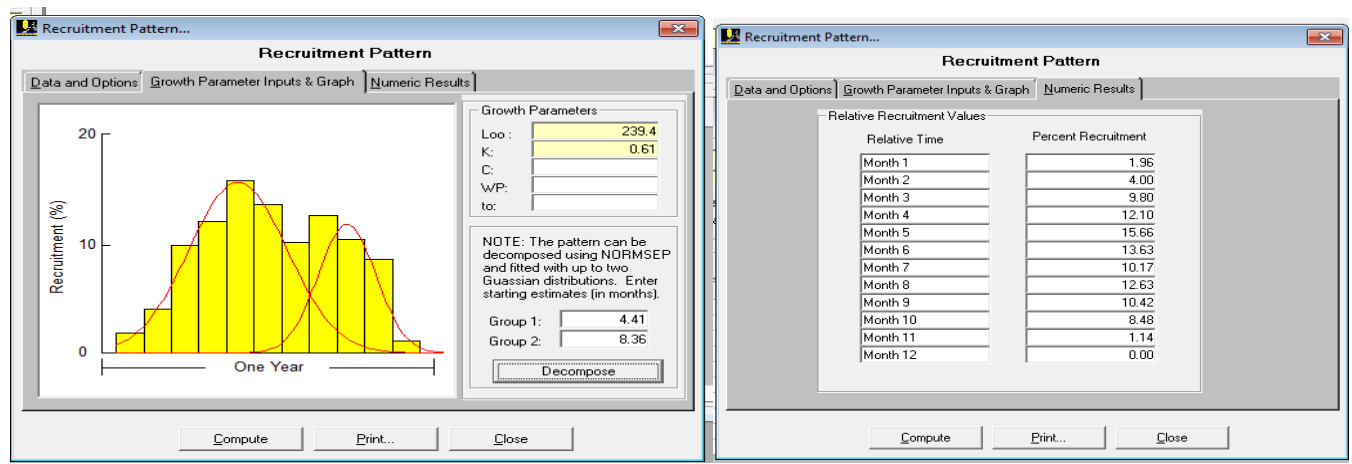

Gambar 7 Parameter dan nilai pertumbuhan ikan kerapu merah (Plectropomus leopardus) selama satu tahun di sekitar perairan Pulau Nusa Manu dan Nusa Leun

Berdasarkan perhitungan nilai rekruitmen pada kedua jenis ikan, dapat diketahui bahwa puncak rekruitmen pada ikan kuwe/bubara terjadi pada bulan 5 dan bulan 8, sedangkan ikan kerapu merah terjadi pada bulan 4 dan 9. Hal ini diduga pada bulan itu sejalan dengan musim pemijahan kedua jenis ikan tersebut sehingga banyak individu baru yang masuk ke dalam perairan. Selain itu rekruitmen jenis ikan ini juga dapat dipengaruhi oleh kondisi lingkungan perairan Pulau Nusa Manu dan Nusa Leun yang subur dengan jumlah fitoplankton yang melimpah dan biasanya terjadi saat permulaan musim timur (Mei-Agustus) sedangkan pola rekruitmen ini cenderung menurun saat memasuki musim pancaroba (September-Oktober) sampai pada saat pergantian musin barat (November-Februari).

\section{Laju Mortalitas dan Laju Eksploitasi Ikan Demersal}

Pendugaan laju mortalitas total (Z) dilakukan dengan metode kurva hasil tangkapan yang dilinearkan sehingga berbasis data panjang. Laju mortalitas total (Z) dapat diduga dari kurva hasil tangkapan yang dikonversikan ke data komposisi panjang yang diliniearkan sesuai dengan pernyataan (Sparre dan Venema 1999) bahwa mortalitas (Z) terdiri dari mortalitas akibat kematian alami (M) dan mortalitas akibat adanya penangkapan (F). Laju eksploitasi sumberdaya ikan diduga melalui hubungan antara mortalitas alami (M) dan mortalitas penangkapan (F).

Laju eksploitasi dianalisis dengan menggunakan data panjang ikan bubara (Caranx sexfaciatus) dan ikan kerapu merah (Plectropomus leopardus) sehingga perhitungannya disesuaikan dengan data biologi dari kedua jenis ikan tersebut. Data biologi yang digunakan merupakan data dari hasil tangkapan ikan yang didaratkan pada pasar tradisional Negeri Sawai. Nilai mortalitas alami (M), 
penangkapan (F), total (Z), dan laju eksploitasi (E). Untuk lebih jelas laju eksploitasi hasil tangkapan ikan dominan diperoleh dapat dilihat pada Tabel 1.

Tabel 1 Mortalitas dan laju eksploitasi ikan demersal

\begin{tabular}{lcccc}
\hline \multirow{2}{*}{ Jenis Ikan } & \multicolumn{4}{c}{ Mortalitas } \\
\cline { 2 - 5 } & $\mathrm{Z}($ /tahun) & $\mathrm{M}($ /tahun) & $\mathrm{F}($ /tahun) & $\mathrm{E}(\%)$ \\
\hline Kuwe/Bubara (Caranx sexfaciatus) & 0,92 & 0,44 & 0,47 & 52 \\
Kerapu merah (Plectropomus leopardus) & 1,15 & 0,53 & 0,62 & 54 \\
\hline
\end{tabular}

Berdasarkan Tabel 1, diketahui bahwa rata-rata nilai mortalitas penangkapan pada ikan kuwe/bubara (Caranx sexfaciatus) dan kerapu merah (Plectropomus leopardus) lebih besar yaitu dari 0,47-0,62 dibandingkan nilai mortalitas alaminya yaitu sebesar 0,44-0,53. Pendugaan laju mortitas ikan di kawasan fishing ground Pulau Nusa Manu dan Nusa Leun yaitu dengan melihat jenis ikan hasil tangkapan yang dominan diperoleh sehingga pendugaan ini mewakili status eksploitasi ikan demersal dalam kawasan kedua pulau tersebut. Artinya bahwa ikan demersal yang didaratkan di pasar tradisional Negeri Sawai lebih banyak mati akibat aktivitas penangkapan.

Dari hasil ini juga dapat diketahui bahwa laju eksploitasi pada ikan demersal secara umum yang tertangkap mulai mengalami over eksploitasi, di mana laju eksploitasi cenderung meningkat dan berada pada nilai 0,52-0,54 atau sebesar 52\%-54\%. Hal ini sesuai dengan pernyataan (Noija el at. 2014) bahwa tingkat pemanfaatan sumberdaya ikan kerapu dan ikan kuwe/bubara di perairan Ambon dan Maluku masih berada pada potensi lestari untuk dikembangkan, tetapi perlu adanya pengawasan dan pengaturan pemanfaatannya agar dapat menjamin keberlanjutan sumberdaya ikan demersal di sekitar kawasan tersebut. Lebih lanjut dijelaskan (Gulland 1971; Pauly 1984; dalam Agustina 2015) jika laju eksploitasi melebihi nilai optimum 0,5 atau $>50 \%$, maka hal ini mengidentifikasikan suatu sumberdaya ikan mengalami over eksploitasi. Walaupun nilai laju eksploitasi ikan demersal di kawasan kedua pulau tersebut berada di atas 50\%, tapi secara keseluruhan masih berada dalam ketegori terkontrol. Akan tetapi beberapa kegiatan eksploitasi yang tidak terkendali, dapat berpotensi menyebabkan kerusakan lingkungan dan penurunan sumberdaya ikan di kawasan kedua pulau, yang secara perlahan dapat mengancam kelestariannya, sehingga perlu dilakukan pengelolaan sumberdaya ikan demersal secara berkelanjutan (Prihatiningsih et al. 2013).

Dalam rangka pemanfaatan sumberdaya ikan demersal secara berkelanjutan, harus mempertimbangkan beberapa sifat sumberdaya ikan demersal seperti, aktivitas rendah ruaya yang tidak jauh dan laju pertumbuhan individu yang tidak terlalu tinggi (Russo et al. 2013). Sifat tersebut menyebabkan spesies ikan demersal lebih cenderung mengalami tekanan penangkapan jika dibandingkan jenis ikan pelagis, sehingga bila intensitas penangkapan tersebut ditingkatkan, maka kematian ikan karena aktifitas penangkapan juga akan semakin besar.

\section{Pengelolaan Perikanan Demersal}

Alasan paling mendasar dalam pengelolaan sumberdaya ikan demersal di kawasan Pulau Nusa Manu dan Nusa Leun adalah dengan memanfaatkan sumberdaya di dalam kawasan ini, sehingga menghasilkan manfaat ekonomi yang tinggi bagi masyarakat Negeri Sawai dan sekitarnya, namun tetap menjaga kelestarian sumberdaya alam tersebut. Hal ini sesuai dengan pendapat (Nikijuluw 2002; Retraubun 2005; Samudra 2010) bahwa pemanfaatan sumberdaya ikan pada suatu kawasan tertentu, harus dapat dilakukan dengan mengintergrasikan masyarakat sebagai pelaku usaha dan keberadaan sumberdaya alam dalam kawasan tersebut, agar dapat meningkatkan perekonomian masyarakat dan secara berkelanjutan dapat menjamin ketersediaan sumberdaya alam tetap aman. Secara implisit hal ini mengandung dua makna, yaitu makna sosio-ekonomi dan makna konservasi atau eko-biologi. 
Dengan demikian, pemanfaatan optimal sumberdaya ikan mau tidak mau harus mengakomodasi hubungan antar kegiatan tersebut. Beberapa pendekakatan yang dapat dipakai dalam melakukan pengelolaan perikanan ikan demersal secara berkelanjutan di kawasan Pulau Nusa Manu dan Nusa Leun ialah:

\section{Pengaturan Musim Penangkapan Ikan (MPI)}

Pengelolaan kegiatan perikanan tangkap pada kedua pulau ini dilakukan melalui pendekatan pengaturan musim penangkapan ikan pada waktu-waktu ikan memijah dan berkembang dengan melakukan sasi laut (kearifan lokal). Hal ini memerlukan dukungan semua lapisan masyarakat, khususnya masyarakat nelayan yang memanfaatkan sumberdaya di sekitar kawasan kedua pulau, untuk memiliki rasa kepedulian dan disiplin yang tinggi dalam mematuhi dan menjalankan peraturan yang ada (Nikijuluw 2002). Lebih lanjut Beddington dan Retting (1983) menjelaskan, paling tidak ada dua bentuk pengaturan musim penangkapan ikan. Pertama, menutup musim penangkapan ikan pada waktu tertentu untuk memungkinkan ikan dapat memijah dan berkembang. Kedua, penutupan kegiatan penangkapan ikan karena sumberdaya ikan telah mengalami degradasi, dan ikan yang ditangkap semakin sedikit.

\section{Pembatasan Armada dan Alat Tangkap}

Sacara umum alat tangkap ikan yang dipakai oleh nelayan sekitar kedua pulau ialah alat tangkap ikan yang ramah lingkungan yaitu pancing ulur dan pancing tegak, namun demikian jumlah armada penangkapan yang banyak dan berasal dari negeri/desa dan dusun di sekitar kedua pulau menyebabkan kerentanan terhadap daya dukung penangkapan ikan. Pengaturan dalam membatasi armada penangkapan perlu dilakukan dalam kawasan perairan kedua pulau tersebut. Untuk pelarangan jenis alat tangkap tertentu dapat dilakukan secara permanen, hal ini dibuat untuk melindungi sumberdaya ikan di sekitar kawasan dari penggunaan alat tangkap yang merusak atau destruktif (potasium sianida dan bom ikan), selain untuk pertimbangan lain yang bertujuan melindungi nelayan kecil/tradisional yang ada di sekitar kawasan Pulau Nusa Manu dan Nusa Leun.

\section{Pengendalian Upaya Penangkapan Ikan}

Pengendalian upaya penangkapan ikan adalah salah satu pendekatan pengelolaan sumberdaya perikanan yang bertujuan untuk meningkatkan hasil tangkapan ikan, kinerja ekonomi nelayan penangkap ikan melalui pengurangan upaya atau kapasitas penangkapan ikan yang berlebihan. Pendekatan lain yang dapat dilakukan dalam mengendalikan upaya penangkapan ikan adalah penentuan jumlah unit penangkapan ikan yang diperbolehkan melalui pengaturan perijinan. Pengelolaan perikanan demersal perlu disesuaikan berdasarkan kegiatan penangkapan ikan dari sebelumnya setiap bulan ke sistem kuota kapal atau Vessel Quota Share (VQS) yaitu sebuah bentuk kegiatan penangkapan ikan yang dapat berganti oleh setiap nelayan, di mana ijinnya terkait dengan armada penangkapan ikan. Hal ini dilakukan agar dapat mengatur jumlah hasil tangkapan ikan dengan harga pembelian yang sesuai sehingga perijinan kapal dapat diatur secara berkala (Mortensen et al. 2018). Upaya yang strategis dilakukan untuk meningkatkan kemampuan nelayan tradisioal di kawasan Pulau Nusa Manu dan Nusa Leun sebagai berikut: 1. Pemberdayaan nelayan Negeri Sawai dan sekitarnya dalam wadah koperasi; 2. Motorisasi nelayan tradisional; 3. Pola kemitraan inti plasma; dan 4. Pengaturan zona penangkapan ikan untuk meminimalisir konflik sosial antar nelayan dan menghindari kerusakan ekosistem yang berakibat pada turunnya ketersediaan sumberdaya ikan pada kawasan Pulau Nusa Manu dan Nusa Leun.

Berkaitan dengan pemahaman di atas, arti penting pelestarian lingkungan bagi masyarakat yang memanfaatkan kawasan Pulau Nusa Manu dan Nusa Leun ialah dengan menumbuhkan kembali kearifan lokal (sasi laut) yang sempat hilang dan hanya diberlakukan pada wilayah darat (kebun). Tindakan nyata bentuk pelestarian sumberdaya alam dan ekosistem oleh masyarakat Negeri Sawai dapat tercermin dalam perilaku ramah lingkungan sehari-hari. Berdasarkan pengamatan dan hasil 
wawancara, perilaku ramah lingkungan masyarakat Negeri Sawai dan dusun-dusun tetangga pada kawasan kedua pulau ini tidak terlepas dari peran tokoh masyarakat/adat dan tokoh agama di wilayah setempat.

Kearifan lokal itu seperti "Petuanan" yakni menghormati negeri adat sebagai negeri awal yang memiliki luas dan batasan wilayah pengelolaan mencangkup beberapa desa dan dusun sekitarnya. Ada ruang pengelolaan tertentu yang telah diatur berdasarkan keputusan adat negeri dalam pembagian wilayah khusus pengelolaan negeri serta untuk masyarakat umum. Seperti contohnya masyarakat secara hukum adat diatur agar tidak melakukan pengambilan sumberdaya alam pada lokasi-lokasi tertentu seperti pada ekosistem mangrove, pasir pantai, terumbu karang bahkan ruang laut untuk budidaya. Jika terjadi pelanggaran maka akan dijatuhi hukuman berdasarkan aturan hukum adat negeri. Kegiatan penangkapan ikan menggunakan alat kompresor dengan cara destruktif menggunakan racun potasium (sianida) dan penggunaan bahan peledak (bom) dilarang keras dan diawasi bersama-sama oleh masyarakat sekitar kawasan kedua pulau ini. Bagi masyarakat dari luar kawasan yang tertangkap melakukan aktivitas merusak lingkungan, diserahkan kepada pihak yang berwajib untuk diproses secara hukum formal yang berlaku.

\section{KESIMPULAN DAN SARAN}

\section{Kesimpulan}

Berdasarkan hasil penelitian, dapat disimpulkan:

1. Lokasi fishing ground potensial bagi nelayan tradisional yang memanfaatkan kawasam Pulau Nusa Manu dan Nusa Leun umumnya berada pada daerah ekosistem terumbu karang, hingga ke arah utara Laut Seram dengan jarak 2 mil laut. Jenis ikan hasil tangkapan didominasi oleh ikan kuwe/bubara (Caranx sexfaciatus) dan kerapu merah (Plectropomus leopardus).

2. Memiliki bentuk pertumbuhan (rekruitmen) sepanjang tahun dengan laju eksploitasi yang cenderung meningkat. Untuk itu perlu dilakukan pengaturan dan pembatasan eksploitasi sumberdaya ikan tersebut, agar menjamin ketersediaan stok dan keberlanjutan sumberdaya ikan demersal dalam kawasan Pulau Nusa Manu dan Nusa Leun.

Saran

Pemanfaatan lokasi fishing ground potensial ikan demersal di sekitar kawasan Pulau Nusa Manu dan Nusa Leun perlu disesuaikan dengan aktiftas pemanfaatan lainnya, mengingat pada kawasan ini terdapat zona pemanfaatan untuk aktifitas budidaya KJA dan ekowisata bahari. Pengelolaan perikanan demersal perlu mendapat dukungan dari seluruh stakeholder yang berkepentingan pada kawasan tersebut.

\section{DAFTAR PUSTAKA}

Ayal FW. 2009. Kajian Perairan Pesisir Desa Sawai Kabupaten Maluku Tengah bagi Pengembangan Ekowisata. [tesis]. Bogor (ID): Institut Pertanian Bogor.

Agustina S. 2015. Pengelolaan Multispesies Sumber Daya Ikan Demersal pada Perikanan Jaring Arad di Perairan Selat Sunda [tesis]. Bogor (ID): Institut Pertanian Bogor.

Antje G, Vanessa S, Britta G. 2015. A GIS Modelling Framework to Evaluate Marine Spatial Planning Scenarios: Co-Location of Offshore Wind Farms and Aquaculture in The German EEZ.

Ban and Klein. 2009. Spatial Socio-Economic Data as a Cost in Systematic Marine Conservation Planning. Conserv. Lett. 2 (5): 206-215. 
Beddington, J.R. and B. Retting. 1983. “Approaches to the Regulation of Fishing Effort" FAO Fisheries Technical Paper. 243:39.

BPS. 2016. Maluku Tengah dalam Angka. Badan Pusat Statistik Kabupaten Maluku Tengah Tahun 2016. Masohi.

Budiman. 2006. Analisis Sebaran Ikan Demersal sebagai Basis Pengelolaan Sumberdaya Pesisir di Kabupaten Kendal [tesis]. Semarang (ID): Universitas Diponegoro.

Coll M, Piroddi C, Steenbeek J, Kaschner K, Lasram F.B.R, Aguzzi J, Vafidis D, Villanueva R, Voultsiadou E. 2010. The biodiversity of the Mediterranean Sea: forecasts, patterns, and threats. J PLoS One. 2.5 (8):e11842

Dinas Kelautan dan Perikanan Kabupaten Maluku Tengah. 2016. Statistik Perikanan Kabupaten Maluku Tengah. Masohi.

Dinas Kelautan dan Perikanan Kabupaten Maluku Tengah. 2014. Statistik Perikanan Kabupaten Maluku Tengah. Masohi.

Effendie MI. 1979. Metode Biologi Perikanan. Bogor (ID): Yayasan Dewi Sri Cikuray

Gulland JA. 1983. Fish Stock Assesment: Manual of Basic Method. New York : Wiley and Sons Interscience. Volume 1, FAO/Wiley Series on Food and Agricultural.

Halpern S, Walbridge S, Selkoe KK, Kappel CV, Steneck R, Watson R. 2008. A Global Map of Human Impact on Marine Ecosystems Science. Jdu Conse 319 (68): 948-953.

Kartini N. 2017. Pola Rekrutmen, Mortalitas dan Laju Eksploitasi Ikan Lemuru (Amblygaster sirm, Walbaum 1792) di Perairan Selat Sunda. J Bios. 10 (1): 11 - 16.

Katsanevakis SV, Stelzenmüller A, South, Sorensen Kindergarten TV, Fernandez S. Voge A. Weber A, Zenetos R, Hofstede. 2011. Marine Based Marine Space Management Ecosystem: review of concepts, policies, tools, and critical issues The Ocean. Coast. Manag. 54 (11): 807-820.

Mazor T, Giakoumi S, Kark S. 2014. Possingham Massive Conservation Planning in a Multinational Marine Environment: The Cost Ecol. Appl. 24 (5): 1115-1130 .

Mayunar 1994. Status Keberhasilan Pembenihan Ikan Kerapu Sunu di Indonesia dan Prospek Pengembangannya. J. Oseana. 24 (4): 23 - 33

Micheli F. Halpern BS, Walbridge S, Ciriaco S, Ferretti F, Fraschetti S, Lewison R, Nykjaer L, Rosenberg AA. 2013. Cumulative Human Impact on Mediterranean and Black Sea ecosystems: assess current pressures and opportunities. J PLoS One. 4:8 (12): e79889

Mortensen OL, Ulrich C, Hansen J, Hald R. 2018. Identifying Choke Species Challenges for an Individual Demersal Trawler in the North Sea, Lessons from Conversations and Data Analysis. Mar. Resour. Econ. 87 (25): 11-22

Najamuddin. 2012. Keragaman Ikan Karang di Perairan Pulau Makian Provinsi Maluku Utara . J Depik 1(2): 114-120.

Nikijuluw VPH. 2002. Rezim Pengelolaan Sumberdaya Perikanan. Jakarta (ID): PT. Pustaka Cidesindo.

Noija D, Martasuganda S, Murdiyanto B, Taurusman AA. 2014. Potensi dan Tingkat Pemanfaatan Sumberdaya Ikan Demersal di Perairan Pulau Ambon Provinsi Maluku. JTPK. 5 (1): 55-64

Nybakken J.W. 1988. Biologi laut. Suatu Pendekatan Ekologis. Jakarta (ID): Gramedia.

Omar SBA. 2012. Dunia Ikan. Jogjakarta (ID): UGM Pr. 
Pauly D. 1984. Fish Population Dynamic in Tropical Waters: a Manual for Use with Progfammable Calculators. ICLARS Stud, Rev (8): 325.

Rifai U, Samal K. 2013. Kajian Prospek dan Kelayakan Pengembangan Usaha Budidaya Ikan Bubara (Caranx sp) di Teluk Kotania Kabupaten Seram Bagian Barat. Ambon (ID): Balai Budidaya Laut.

Prihatiningsih, Sadhomotomo B, dan Taufik M. 2013. Dinamika Populasi Ikan Swanggi (Priancathus tayenus) di Perairan Tanggerang-Banten. JBAWAL. 5 (2): 81-87.

Purbayanto A, Riyanto M, Fitri ADP. 2010. Fisiologi dan Tingkah Laku Ikan pada Perikanan Tangkap. Bogor (ID): IPB Pr.

Retraubun ASW. 2005. Pengelolaan Pulau-pulau Kecil di Indonesia. Makalah disampaikan pada Pelatihan Pelatih untuk Pelatih Pengelolaan Wilayah Pesisir Terpadu. Bogor, 8-9 Maret 2005. $29 \mathrm{hlm}$.

Russo T, Parisi A, Prorgi M, Boccoli F, Cignini I, Tordoni M, Cataudella S. 2013. When the Behavior Rreveals the Aactivity: Commissioning a Capture Attempt for Métiers Based on VMS Data Using Artificial Neural Networks Fish. Res. 111 (1-2): 53-64.

Samudra K. 2010. Pola Pengelolaan Gugusan Pulau-Pulau Kecil di Kawasan Kapoposan yang Berkelanjutan [disertasi]. Bogor (ID): Institut Pertanian Bogor

Simbolon D. 2011. Bioekologi dan Dinamika Daerah Penangkapan Ikan. Bogor (ID): IPB Pr

Sparre P, dan Venema S.C. 1999. Introduksi Pengkajian Stok Ikan Tropis, Buku I: Manual. Widodo J, Meta I.G.S, Nurhakim S, Baharudin M. Jakarta: Pusat Penelitian dan Pengembangan Perikanan. Terjemahan dari Introduction to Tropical Fish Stock Assassment. Part I: Manual. Jakarta (ID): FAO

Sudirman dan Mallawa A. 2012. Teknik Penangkapan Ikan. Jakarta (ID): PT. Rineka Cipta Jakarta.

Tuwo A. Tresnati J. Parawansa B.S. 2012. Analisis Kelayakan Pengembangan Ekowisata Selam dan Snorkeling di Kepulauan Tanakeke. J Sains Teknol. 9 (2): 218 - 225.

Ulrich C, Reeves SA, Vermard Y, Holmes SJ , Vanhee W. 2011. Reconciliation of Single Species TAC in the North Sea Demersal Fishery using Fcube Fishery Mixture Suggestion Framework. ICES. JMar. Sci 68 (10): 1535 - 1547.

Wudji A, Suwarso, Wudianto. 2013. Biologi Reproduksi dan Musim Pemijahan Ikan Lemuru (Sardinella lemuru Bleeker 1853) di Perairan Selat Bali. JBAWAL. 5(1): 49-57. 